\title{
Molecular analysis for investigating dietary habits: genetic screening of prey items in scat and stomach contents of leopard cats Prionailurus bengalensis euptilurus
}

\author{
Ohsun Lee, Sua Lee, Dong-Ha Nam and Hak Young Lee*
}

\begin{abstract}
Background: Among the Felidae recorded on the Korean Peninsula, the tiger Panthera tigris, leopard Panthera pardus, and lynx Lynx lynx are now endangered, while the leopard cat Prionailurus bengalensis, the remaining feline, is a globally threatened carnivore. Herein, we investigated the dietary habits of leopard cats by analyzing prey DNA in scat and stomach contents. We also tested whether prey DNA in scat samples collected from natural habitats could accurately identify prey species from stomach contents.

Results: Following a visual analysis of stomach contents from 11 leopard cats killed on the roads, a molecular analysis of the cytochrome $b$ gene of the mitochondrial genome of 56 subsamples of the stomach contents enabled the identification of 7 mammalian species, 1 bird species, and 1 amphibian species. In the analysis of several blind subsamples (e.g., bones) isolated from fecal samples, five prey species were identified using control markers in a denaturing gradient gel electrophoresis (DGGE) technique and an additional sequencing analysis.

Conclusions: Our results suggest that the DGGE analysis can serve as a potential tool to study diets, raising the possibility of a non-invasive approach for studying dietary habits of leopard cats.
\end{abstract}

Keywords: Leopard cat; Stomach contents; DGGE; Fecal analysis; Korea

\section{Background}

There are 12 subspecies of the leopard cat Prionailurus bengalensis, and they significantly differ in appearance and choice of habitat. Prionailurus bengalensis euptilurus is the only subspecies reported to live in Manchuria (China), eastern Russia, Tsushima (Japan), and Korea (Nowell and Jackson 1996). The leopard cat is listed and protected under the Convention on International Trade in Endangered Species of Wild Fauna and Flora (CITES) Appendices I and II; specifically, P. bengalensis in India, Bangladesh, and Thailand is listed in CITES Appendix I because of its low abundance, while $P$. bengalensis in other areas is listed in Appendix II (Nowak 1999). The subspecies $P$. bengalensis euptilurus is designated a class II endangered species, as it is almost extinct in Korea.

\footnotetext{
* Correspondence: dongha@jnu.ac.kr; haklee@jnu.ac.kr

Department of Biological Sciences, College of Natural Sciences, Chonnam National University, 77 Yongbong-ro Bukgu, Gwangju 500-757, South Korea
}

The leopard cat is a charismatic megafauna, with appealing characteristics; however, it is also vulnerable to extinction due to habitat loss and persecution. Determining the feeding habits of this feline species may be a key factor in ecological studies and conservation efforts (Farrell et al. 2000). Dietary habits of the leopard cat have been studied in Thailand (Rabinowitz 1990; Grassman 2000; Austin 2002; Grassman et al. 2005), Tsushima, Japan (Tatara and Doi 1994), and the Philippines (Fernandez and De Guia 2010). However, determining such dietary habits was contingent on morphological identification in conjunction with microscopic hair analysis of prey items. Although molecular scatology was successfully undertaken to determine species-specific DNA in some captive (e.g., Steller sea lions) and other wild mammals (e.g., the jaguar and puma; Farrell et al. 2000; Deagle et al. 2005), this genetic screening technique has not been applied to wild leopard cats. 
Herein, we used a molecular analysis to study dietary habits of leopard cats in Korea from scat and stomach contents. We also investigated whether genetic screening using a denaturing gradient gel electrophoresis (DGGE) technique can accurately identify prey DNA, compared to DNA sourced from stomach contents. We determined that molecular scatology provided reliable information on prey preferences of leopard cats and may contribute to the current need for conservation and management strategies for this globally threatened wild population.

\section{Methods}

\section{Samples}

Between October 2005 and September 2006, the stomachs of 11 dead leopard cats were collected along the roads in Gurye, Korea (Table 1). When a leopard cat was found killed on the road, its coordinates were marked using a GPS (Sportrak MAP, Magellan SporTrak, Thales Navigation, San Dimas, CA, USA); the gender, date, and elevation were recorded; and a photograph (Nikon D70, Tokyo, Japan) of the specimen was taken. The stomachs were stored at $-70^{\circ} \mathrm{C}$ until being analyzed. Digested stomach contents were visually analyzed and also subjected to a molecular analysis.

Scat from leopard cats was differentiated from scat of other small carnivores in terms of the shape and size and/or the presence of species-specific tracks (Grassman et al. 2005). An average diameter of $1 \mathrm{~cm}$ for the scat of the leopard cat was used as a reference. Assuming that cannibalism did not occur (Grassman et al. 2005), another criterion for identifying leopard cat scat was the presence of hair ingested while auto-grooming. The diet of leopard cats was investigated via analysis of their scat. Scat was collected from Samcheok in 2006, Goheung in 2011, and Gwangju in 2011 in Korea (Table 1). The scat was placed in a fine mesh nylon stocking and washed to separate the contents. The contents were then sun-dried and stored in $70 \%$ alcohol.

\section{DNA extraction}

Twenty-five milligrams of each individual tissue, toe, and tail sample from the stomach contents was isolated. Bone samples from the scat of leopard cats were carefully cleaned using a disposable scalpel and compressed air and were ground to a fine powder in a small mortar. DNA was extracted from the bone powder, tissue, toe, and tail samples using a QIAamp Blood \& Tissue Kit (Qiagen, Valencia, CA, USA), according to the manufacturer's instructions. DNA was extracted from 61 samples (56 distinct subsamples from stomach contents and 5 blind subsamples from bones isolated from scat).

\section{Standard polymerase chain reaction}

A standard polymerase chain reaction (PCR) was performed using a DNA amplification kit AccuPower ${ }^{\oplus}$ HotStart PCR PreMix (Bioneer, Daejeon, Korea) with primers for the complete human mitochondrial DNA sequences L14841 (5' -AAAAAGCTTCCATCCAACATCTCAGCAT GATGAAA-3') and H15149 (5'-AAACTGCAGCCCCTC

Table 1 Preparations of stomach contents from road-killed specimens and fecal samples of the leopard cat $P$. bengalensis

\begin{tabular}{|c|c|c|c|c|c|c|}
\hline & Order & Date & Latitude & Longitude & Elevation (m) & Contents \\
\hline \multirow[t]{11}{*}{ Stomach contents } & 1 & 18 October 2005 & $35^{\circ} 30^{\prime} 11.78^{\prime \prime} \mathrm{N}$ & $127^{\circ} 31^{\prime} 40^{\prime \prime} \mathrm{E}$ & 210 & Apodemus agrarius, plant, insect, parasite \\
\hline & 2 & 24 October 2005 & $35^{\circ} 29^{\prime} 16.83^{\prime \prime} \mathrm{N}$ & $127^{\circ} 29^{\prime} 21.93^{\prime \prime} \mathrm{E}$ & 211 & Rattus norvegicus, plant \\
\hline & 3 & 20 November 2005 & $35^{\circ} 28^{\prime} 40.93^{\prime \prime} \mathrm{N}$ & $127^{\circ} 28^{\prime} 39.18^{\prime \prime} \mathrm{E}$ & 213 & Crocidura shantungensis, Apodemus agrarius, fish \\
\hline & 4 & 5 December 2005 & $35^{\circ} 12^{\prime} 11.08^{\prime \prime} \mathrm{N}$ & $127^{\circ} 29^{\prime} 37.08^{\prime \prime} \mathrm{E}$ & 25 & Rattus norvegicus, Monopterus albus \\
\hline & 5 & 8 January 2006 & $35^{\circ} 29^{\prime} 44.24^{\prime \prime} \mathrm{N}$ & $127^{\circ} 30^{\prime} 40.92^{\prime \prime} \mathrm{E}$ & 231 & Rattus norvegicus, Phasianus colchicus, parasite \\
\hline & 6 & 17 February 2006 & $35^{\circ} 24^{\prime} 21.4^{\prime \prime} \mathrm{N}$ & $127^{\circ} 25^{\prime} 11.6^{\prime \prime} \mathrm{E}$ & 128 & Tamias sibiricus \\
\hline & 7 & 30 April 2006 & $35^{\circ} 11^{\prime} 42.01^{\prime \prime} \mathrm{N}$ & $127^{\circ} 36^{\prime} 49.29^{\prime \prime} \mathrm{E}$ & 15 & Apodemus agrarius \\
\hline & 8 & 18 May 2006 & $35^{\circ} 26^{\prime} 35.9^{\prime \prime} \mathrm{N}$ & $127^{\circ} 26^{\prime} 4.22^{\prime \prime} \mathrm{E}$ & 128 & $\begin{array}{l}\text { Crocidura shantungensis, Crocidura lasiura, } \\
\text { Apodemus agrarius, Rattus norvegicus, } \\
\text { Micromys minutus, Rana nigromaculata, insect }\end{array}$ \\
\hline & 9 & 20 May 2006 & $35^{\circ} 13^{\prime} 17.8^{\prime \prime} \mathrm{N}$ & $127^{\circ} 28^{\prime} 07.4^{\prime \prime} \mathrm{E}$ & 133 & Sciurus vulgaris, Tamias sibiricus, parasite \\
\hline & 10 & 31 August 2006 & $35^{\circ} 11^{\prime} 40.84^{\prime \prime} \mathrm{N}$ & $127^{\circ} 36^{\prime} 50.74^{\prime \prime} \mathrm{E}$ & 14 & Rattus norvegicus, Apodemus agrarius \\
\hline & 11 & 30 September 2006 & $35^{\circ} 13^{\prime} 31.59^{\prime \prime} \mathrm{N}$ & $127^{\circ} 27^{\prime} 36.77^{\prime \prime} \mathrm{E}$ & 33 & Empty \\
\hline \multirow[t]{4}{*}{ Scat } & 1 & 22 July 2006 & $37^{\circ} 12^{\prime} 51.00^{\prime \prime} \mathrm{N}$ & $129^{\circ} 08^{\prime} 54.00^{\prime \prime} \mathrm{E}$ & 895 & Turdus pallidus, Rattus norvegicus \\
\hline & 2 & 25 October 2011 & $34^{\circ} 28^{\prime} 55.57^{\prime \prime} \mathrm{N}$ & $127^{\circ} 27^{\prime} 18.57^{\prime \prime} \mathrm{E}$ & 47 & Apodemus agrarius, Rattus norvegicus \\
\hline & 3 & 30 September 2011 & $35^{\circ} 05^{\prime} 38.10^{\prime \prime} \mathrm{N}$ & $126^{\circ} 56^{\prime} 16.95^{\prime \prime} \mathrm{E}$ & 106 & Apodemus agrarius, Micromys minutus \\
\hline & 4 & 28 November 2011 & $35^{\circ} 06^{\prime} 06.01^{\prime \prime} \mathrm{N}$ & $126^{\circ} 56^{\prime} 16.86^{\prime \prime} \mathrm{E}$ & 90 & Phasianus colchicus \\
\hline
\end{tabular}


AGAATGATATTTGTCCTCA-3') (Kocher et al. 1989) to amplify a 307-bp fragment of the cytochrome $b$ gene. To each sample, $2 \mu \mathrm{l}$ of a genomic DNA template was added. The PCR conditions were as follows: 40 cycles of denaturation at $94^{\circ} \mathrm{C}$ for $1 \mathrm{~min}$, annealing at $51^{\circ} \mathrm{C}$ for $1 \mathrm{~min}$, and extension at $72^{\circ} \mathrm{C}$ for $2 \mathrm{~min}$. Samples were separated using $2.0 \%$ agarose gels.

\section{DGGE analysis}

In order to identify additional sequences in our PCR products, we used DGGE, a technique that can separate various DNA sequences (Myers et al. 1987). Separation is accomplished by electrophoresis of the DNA fragments using a polyacrylamide gel that contains a gradient with an increasing concentration of denaturants. The mobility of the fragments is determined by their melting behavior as they denature, and this is highly sequence dependent. DGGE was performed using the V20-HCDC system (Scie-Plas, Southampton, UK). For samples separated using DGGE, the GC-L14841 primer (5'-CGCCCGCCGCGCCCCGCGCCCGTCCCGCCGC CCCCGCCCGAAAAAGCTTCCATCCAACATCTCAGC ATGATGAAA-3') was redesigned to incorporate a G-C clamp (Kocher et al. 1989), and the annealing temperature was lowered to $50^{\circ} \mathrm{C}$. The other PCR conditions remained the same as those used for the standard PCR. The template was $1 \mu \mathrm{l}$ of a 1:10 dilution of the unclamped PCR product.

PCR products were directly loaded onto $8 \%$ polyacrylamide gels submerged in $1 \times$ TAE buffer $(40 \mathrm{mM}$ Tris acetate at $\mathrm{pH} 7.4,20 \mathrm{mM}$ sodium acetate, and $1 \mathrm{mM}$ EDTA). The gels were prepared with a denaturant gradient of 35\% 64\% (7 M urea; GIBCO-BRL, Grand Island, NY, USA) and $40 \%$ deionized formamide ( $v / v$; SigmaAldrich, St. Louis, MO, USA). Electrophoresis was performed at a constant voltage of $70 \mathrm{~V}$ and temperature of $56^{\circ} \mathrm{C}$ and was run for $15 \mathrm{~h}$. After electrophoresis, the gels were incubated for $15 \mathrm{~min}$ in distilled water containing ethidium bromide $(0.5 \mathrm{mg} / \mathrm{ml})$, rinsed for $10 \mathrm{~min}$ with distilled water, and photographed using the SynGene Genius system (Core Bio system, Seoul, Korea). Prior to sequencing, the PCR products were purified using a QIAquick PCR purification kit (Qiagen), according to the manufacturer's instructions.

\section{DGGE band analysis}

DGGE bands were excised using a sterile scalpel and transferred to $30 \mu \mathrm{l}$ of sterile distilled water. This solution was stored overnight at $4^{\circ} \mathrm{C}$, before a $1-\mu \mathrm{l}$ aliquot was used to re-amplify (with a PCR) the isolated product with the original primer set (without the primer GCclamp sequence) using the same amplification conditions described above. The PCR products were verified using agarose gel electrophoresis and were then purified using the QIAquick PCR purification kit (Qiagen), according to the manufacturer's instructions.

\section{Sequence analysis}

Sequencing was performed using the L14841 and H15149 primer sets at Genotech (Daejeon, Korea). The DNA sequences were compared with publicly available sequences in GenBank using the basic local alignment search tool (Altschul et al. 1990).

\section{Results}

\section{Stomach contents}

Using a visual analysis, 13 taxonomic groups were identified from the contents of all stomachs, except for one (which was empty). The 56 distinct subsamples collected from the stomach contents of leopard cats were successfully amplified and sequenced (Figure 1). Although a few samples contained unreadable base pairs, these were determined by running reverse sequences. The primers used in the analysis are known to amplify the cytochrome $b$ gene of the mitochondrial genome in a wide variety of vertebrates and invertebrates (Kocher et al. 1989). We identified seven species of mammals (Crocidura lasiura [GenBank:HQ709233.1], max indent 92\%; Crocidura shantungensis [GenBank:HQ709233.1], max indent 99\%; Sciurus vulgaris [GenBank:JQ395054.1], max indent 98\%; Tamias sibiricus [GenBank:HQ214041.1], max indent 98\%; Apodemus agrarius [GenBank:HM034888.1], max indent 99\%; Micromys minutus [GenBank:AB125088.1], max indent 99\%; and Rattus norvegicus [GenBank:JX105356.1], max indent 99\%), one species of bird (Phasianus colchicus [GenBank:AY368054.1], max indent 97\%), and one species of amphibian (Rana nigromaculata [GenBank:AY803895.1], max indent 96\%) (Figure 1). Mammals were the most common species identified, with eight specimens of $C$. shantungensis and five specimens of $R$. norvegicus recorded.

\section{DGGE analysis}

The DGGE analysis allowed the identification of eight prey species (C. shantungensis, S. vulgaris, T. sibiricus, $A$. agrarius, $M$. minutus, $R$. norvegicus, $P$. colchicus, and $R$. nigromaculata) (Figure 2a). Amplification of each species produced a single band that did not migrate with any of the other prey bands on the DGGE gel. The DGGE analysis of scat samples showed similar results to that from the stomach contents, and lanes 2, 3, and 4 could be identified as one of the eight taxa from the stomach contents (Figure 2b). Lanes 1 and 5 did not match any of the samples from the stomach contents, and therefore, these two bands were cut from the gel and sequenced; their identities were confirmed to be Turdus pallidus ([GenBank:EU154651.1], max indent 96\%) and $R$. norvegicus ([GenBank:JX105356.1], max indent 97\%). 

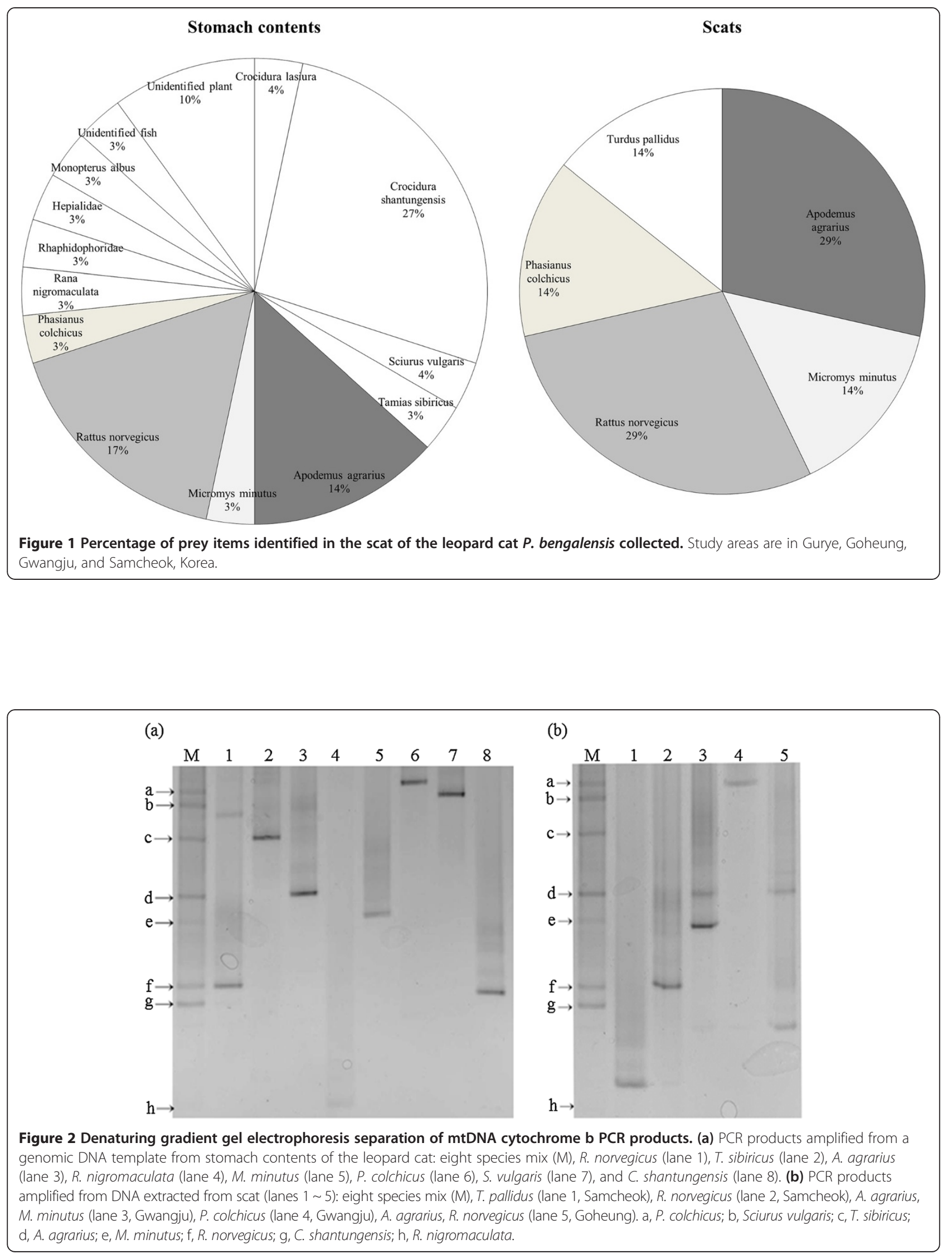


\section{Discussion}

Analysis of the stomach contents revealed 13 prey taxa (Figure 1), eight of which were confirmed using the DGGE analysis (Figure 2a). In the analysis of several blind subsamples (e.g., bones) isolated from fecal samples, five prey species were identified using the DGGE analysis, and all of these items were confirmed to be the same as those observed in the stomach contents (A. agrarius, $M$. minutus, and P. colchicus), except for two bands (Figure 2). These two bands were cut from the gel and sequenced, and their identities were confirmed to be T. pallidus and $R$. norvegicus. $R$. norvegicus showed two different bands in the analysis (Figure 2a, lane 1 and Figure 2b, lane 5); however, sequence analysis identified both bands as $R$. norvegicus. If the same species is affected by a mutation or haplotype, different band patterns can be observed in the DGGE analysis (Kisand and Wikner 2003). PCR-based separations of target DNA are most likely to be affected by the quality of the samples (e.g., a low amount of target DNA and degradation) in the analysis of prey DNA in scat (Taberlet et al. 1999). In the present study, the use of DGGE to separate DNA markers from stomach contents was successful in all five blind subsamples (e.g., bones) from fecal samples (Figure 1). The fecal DGGE analysis also revealed an undetectable prey species (e.g., T. pallidus), which was not identified from stomach contents (Figure 1). Although four prey species were matched between stomach contents and scat samples in the limited sample size (which may have biased the results in terms of the prey frequency of occurrence), our results suggest that the fecal DNA analysis provided an accurate representation of the dietary habits of leopard cats.

Our results showed that $71.6 \%$ of the prey items identified in the stomach contents and scat of the leopard cat were small mammals (Table 1), indicating that these are major prey of this species. These results are consistent with those from Borneo (Rajaratnam et al. 2007), Thailand (Grassman et al. 2005), and Tsushima, Japan (Tatara and Doi 1994), where prey preferences were identified by morphological analyses. The percentage of rodent predation was high, which may be attributable to the relative abundance and availability of rodents throughout the year.

Leopard cat hairs were found in large numbers in stomach and scat samples from the visual analysis and sequencing results (8 of 56 samples analyzed were confirmed as leopard cat hair). Hairs in stomach and scat samples are most likely a result of their own grooming rather than cannibalism (Grassman et al. 2005). Plants comprised $9.1 \%$ of the stomach contents. Given that chimpanzees (Pan troglodytes) and Alaskan brown bears (Ursus arctos) consume high-fiber items to control parasites (Huffman 1997), it is possible that this is the same reason for plant consumption among leopard cats. In addition, a few studies suggested that this phenomenon is an unintentional consequence of feeding on animal prey, and that consumption of plants by the snow leopard Uncia uncia and leopard cat $P$. bengalensis is likely to provide mineral or vitamin supplements, which cannot easily be obtained from animal prey (Shehzad et al. 2012). However, it remains unclear whether the plants were accidentally or intentionally eaten.

Two fish specimens were found in the stomachs of the leopard cats. One was identified as Monopterus albus, but the other specimen could not be identified due to the lack of suitable primer sets for amplifying the target DNA. Although it cannot be ruled out that the leopard cat may have eaten dead fish within their home ranges, these results may be indicative of its ability to swim and catch and eat fish (Lekagul and McNeeley 1977). This is further evident from the fact that fish were found in stomachs of individuals that frequented a riverside in this study (e.g., the Seom-Jin River), as well as the fact that $1.2 \%$ of the prey items of leopard cat scat were determined to be fish by Tatara and Doi (1994).

\section{Conclusions}

The universal primer sets used in this study are suitable for the genetic analysis of mammals, birds, amphibians, reptiles, and some fish (Kocher et al. 1989) but are not appropriate for the analysis of plants or insects. We used a well-known universal primer for chlorophyll (Hofreiter et al. 2000) to analyze specimens of plants in the current study, but unfortunately, the genetic analysis was unsuccessful. When using traditional analytical methods, such as cuticular and medullary patterns of hair and morphological analysis of fecal prey items, it is difficult to identify prey items to the species level; however, the use of sequencing in conjunction with the DGGE technique enables efficient identification to species level. Compared to traditional sequencing, the costs and time required to perform the analysis are reduced, because sequencing is only required for those samples which cannot be identified via the DGGE analysis. In addition, DGGE analyses are suitable for identifying multiple species level only one time in feces other than jaw bone and hair. The DGGE analysis has a few limitations in situations where the target DNA has multiple DGGE band patterns within the same species (e.g., $R$. norvegicus), as shown in the present study (Figure 2). Nevertheless, the DGGE analysis may be a useful tool for assessing dietary habits of the leopard cat, as well as those of other species.

\section{Competing interests}

The authors declare that they have no competing interests.

\section{Authors' contributions}

$\mathrm{OL}, \mathrm{SL}, \mathrm{HYL}$, and D-HN carried out the molecular genetic studies, participated in the sequence alignment, and drafted the manuscript. All authors read and approved the final manuscript. 


\section{Acknowledgements}

We thank Bum Jun Jo for his hard work and assistance with the fieldwork. We also extend our thanks to TY Choi, CG Choi, and DG Choi for collecting dead leopard cats.

Received: 27 February 2013 Accepted: 7 October 2013

Published: 21 November 2013

\section{References}

Altschul SF, Gish W, Miller W, Myers EW, Lipman DJ (1990) Basic local alignment search tool. J Mol Biol 215:403-410

Austin SC (2002) Ecology of sympatric carnivores in Khao Yai National Park, Thailand. Ph.D. dissertation, Texas A\&M University-Kingsville and Texas A\&M University, College Station, Texas

Deagle B, Tollit D, Jarman S, Hindell M, Trites A, Gales N (2005) Molecular scatology as a tool to study diet: analysis of prey DNA in scats from captive Steller sea lions. Mol Ecol 14:1831-1842

Farrell LE, Romant J, Sunquist ME (2000) Dietary separation of sympatric carnivores identified by molecular analysis of scats. Mol Ecol 9:1583-1590

Fernandez DAP, De Guia APO (2010) Feeding habits of Visayan leopard cats (Prionailurus bengalensis rabori) in sugarcane fields of Negros Occidental Philippines. Asia Life Sci 20:143-154

Grassman L Jr (2000) Movements and diet of the leopard cat Prionailurus bengalensis in a seasonal evergreen forest in south-central Thailand. Acta Theriol 45:421-426

Grassman LI, Tewes ME, Silvy NJ, Kreetiyutanont K (2005) Spatial organization and diet of the leopard cat (Prionailurus bengalensis) in north-central Thailand. J Zool 266:45-54

Hofreiter M, Poinar HN, Spaulding WG, Bauer K, Martin PS, Possnert G, Paabo S (2000) A molecular analysis of ground sloth diet through the last glaciation. Mol Ecol 9:1975-1984

Huffman MA (1997) Current evidence for self-medication in primates: a multidisciplinary perspective. Am J Phys Anthropol 104(25):171-200

Kisand V, Wikner J (2003) Limited resolution of 165 rDNA DGGE caused by melting properties and closely related DNA sequences. J Microbiol Meth 54:183-191

Kocher TD, Thomas WK, Meyer A, Edwards SV, Pääbo S, Villablanca FX, Wilson AC (1989) Dynamics of mitochondrial DNA evolution in animals: amplification and sequencing with conserved primers. Proc Natl Acad Sci USA 86:6196-6200

Lekagul B, McNeeley J (1977) Mammals of Thailand. Association for the Conservation of. Wildlife, Bangkok

Myers RM, Maniatis T, Lerman LS (1987) Detection and localization of single base changes by denaturing gradient gel electrophoresis. Methods in Enzymology 155:501-527

Nowak RM (1999) Walker's mammals of the world, 6th edn. The Johns Hopkins University Press, Baltimore, MD

Nowell K, Jackson P (1996) Wild cats: status survey and conservation action plan. IUCN, Gland, Switzerland

Rabinowitz A (1990) Notes on the behavior and movements of leopard cats, Felis bengalensis, in a dry tropical forest mosaic in Thailand. Biotropica 22:397-403

Rajaratnam R, Sunquist M, Rajaratnam L, Ambu L (2007) Diet and habitat selection of the leopard cat (Prionailurus bengalensis borneoensis) in an agricultural landscape in Sabah, Malaysian Borneo. J Trop Ecol 23:209-217

Shehzad W, McCarthy TM, Pompanon F, Purevjav L, Coissac E, Riaz T, Taberlet P (2012) Prey preference of snow leopard (Panthera uncia) in South Gobi, Mongolia. PloS One 7:e32104

Taberlet P, Waits LP, Luikart G (1999) Noninvasive genetic sampling: look before you leap. Trends Ecol Evol 14:323-327

Tatara M, Doi T (1994) Comparative analyses on food habits of Japanese marten Siberian weasel and leopard cat in the Tsushima islands, Japan. Ecol Res 9:99-107

doi:10.1186/1810-522X-52-45

Cite this article as: Lee et al:: Molecular analysis for investigating dietary habits: genetic screening of prey items in scat and stomach contents of leopard cats Prionailurus bengalensis euptilurus. Zoological Studies 2013 52:45.

\section{Submit your manuscript to a SpringerOpen ${ }^{\circ}$ journal and benefit from:}

- Convenient online submission

- Rigorous peer review

- Immediate publication on acceptance

- Open access: articles freely available online

- High visibility within the field

- Retaining the copyright to your article 